\title{
White rot fungi 4222 degrade lignocellulose of corn straw
}

\author{
Shuang Hua ${ }^{1, a}$,Yanli Guan ${ }^{2, b}, \mathrm{Li} \mathrm{Li}^{2, \mathrm{~b}}, \mathrm{Yu} \mathrm{Li}^{3, \mathrm{a}}$ \\ ${ }^{1}$ Jilin Agricultural University, Jilin province of china \\ ${ }^{2}$ Microbial research institute of Liaoning, Liaoning province china \\ ahuashuang@21cn.com, liyu160308@163.com
}

Keywords: White rot fungi; Laccase; Lignincellulose

Abstract. The laccase of 4222 produced was investigated to the degradation ability of lignin and cellulose in the corn stalk powder solid Medium. The results showed that laccase peak was later than the liquid culture, arrived $1842.9 \mathrm{U} / \mathrm{L}$ on $15 \mathrm{~d}$. The training period of $30 \mathrm{~d}$, weight loss of powder dry straw was $82.48 \%$, the lignin of $83.57 \%$ and the cellulose of $86.85 \%$ is degraded. 4222 has well ability to degrade of corn stove, and it is as a good candidate for lignin degradation.

\section{Introduction}

Crop straw contains large amounts of cellulose, hemicellulose, and lignin and other organic material, the global crop straw annual output over 2 billion tons, accounts for 5-600 million tons in china, paper pulp, light chemical industry, clean energy, organic fertilizer and feed are abundant potential as cheap raw materials. In consequence, the large amount of straw yield changes with the seasons, low, large volume, inconvenient transportation, most of animals can't directly digest lignocellulose, natural degradation process is very slow, lead to accumulation and waste burning of straw to form directly into the environment, cause environmental pollution and resource waste. [1][2]

White rot fungi is effective in the degradation of plant fiber raw material lignin [3][4], is currently the strongest known ability to degrade lignin in nature, can only under the condition of pure culture lignin will eventually reach the mineralization type of microorganisms. Using the characteristic of the white-rot fungus, has been in the biological pulping, bio bleaching, bleaching effluent, biochemical treatment, and so on [4], some of which have been used for test phase intermediate production, showed a good application prospect [5].

At present, more than 100 laccases from Basidiomycetes and Ascomycetes fungi have been purified and characterized. Laccase purification from plant crude extracts is complex, and for this reason it has not been studied extensively [9]. In addition, Rodriguez Couto and Toca Herrera(2006)[11][13][14] demonstrated in Trametes hirsuta that sequential addition of different carbon sources, such as glucose followed by glycerol, resulted in a higher laccase production rate, compared to cultures supplemented only with glucose or cellulose. Addition of mediators extend the use of laccases for industrial processes related to bioremediation; including delignification of lignocellulosics[10][15].

\section{Test materials}

Strains sources

4222 strains (by screening Microbial research institute of Liaoning province).

Medium

(1) PDA medium(1L): potato $200 \mathrm{~g}, 20 \mathrm{~g}$ of glucose, agar $18 \mathrm{~g}, \mathrm{pH}$ nature, used for preservation 
(2) Basic medium: cornmeal $2.0 \mathrm{~g}$, bean cake powder $2.0 \mathrm{~g},\left(\mathrm{NH}_{4}\right)_{2} \mathrm{SO}_{4} 0.01 \mathrm{~g}, \mathrm{KH}_{2} \mathrm{PO}_{4} 0.2 \mathrm{~g}$, $\mathrm{MgSO}_{4} 0.05 \mathrm{~g}, \mathrm{VB}_{1} 0.05 \mathrm{~g}, \mathrm{H}_{2} \mathrm{O} 100 \mathrm{ml}$.

(3) Straw powder medium: bottle triangle $(100 \mathrm{ml}) 27$, precise add $2.0000 \mathrm{~g}$ of straw powder, $8.0 \mathrm{ml}$ liquid culture medium, the basis of mix, compaction, constitute the material liquid of 1:4 ratio of straw powder solid medium, with plastic film sealed bottle, $121{ }^{\circ} \mathrm{C}$ sterilization $30 \mathrm{~min}$.

Main reagent

ABTS (Sigma).

\section{Test methods}

Extraction and determination of activity of laccase

The determination of laccase activity with reference to the literature [6].

weightless ness rate determination

Determination of weight method is used to cultivate backbone weightlessness rate (GB745-78).

Determination of lignin, cellulose content

Methods of Hui-qin Xue. [10]

\section{Results}

Strain 4222 product laccase ability in straw powder

4222 let stand for 30 d cultivation concentration in straw solid, it secreted laccase see Fig.1. The Fig. 1 showed that under the condition of experiment, when producing laccase peak (1842.9 $\mathrm{U} / \mathrm{L}$ ) on $15 \mathrm{~d}$, and then decreased.

Strain 4222 degradation of ability in straw powder

4222 stand in the straw powder solid medium culture $30 \mathrm{~d}$ in $28{ }^{\circ} \mathrm{C}$, their material weightlessness rate and lignin, cellulose degradation rate of the determination results such as Fig. 2 ( $\mathrm{a}, \mathrm{b}, \mathrm{c}, \mathrm{d}, \mathrm{e}, \mathrm{f})$, in training period in the first $15 \mathrm{~d}$, material weightless ness rate and lignin, cellulose degradation rate of rise is very big, from the $5 \mathrm{~d}-30 \mathrm{~d}$ headway and gradually leveled off, to $5 \mathrm{~d}$, the lignin and cellulose degradation rate was $19.28 \%, 19.87 \%$, to $10 \mathrm{~d}$, lignin and cellulose degradation rate was $50.43 \%, 52.96 \%$, to $20 \mathrm{~d}$, lignin and cellulose degradation rate was $72.83 \%$, $74.37 \%$, to $30 \mathrm{~d}$, lignin and cellulose degradation rate was $83.57 \%, 86.84 \%$. So the strain of lignocellulose degradation ability is very strong.

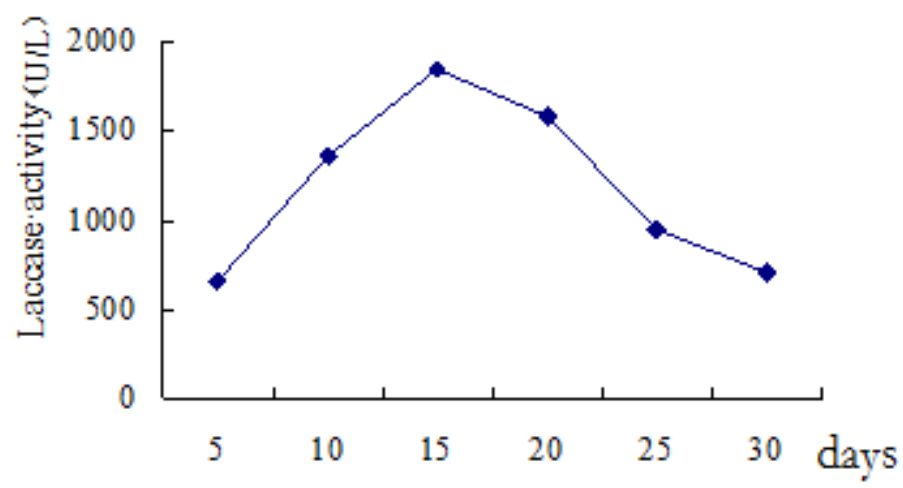

Figure 1 Laccase activity of 4222 in the straw culture 

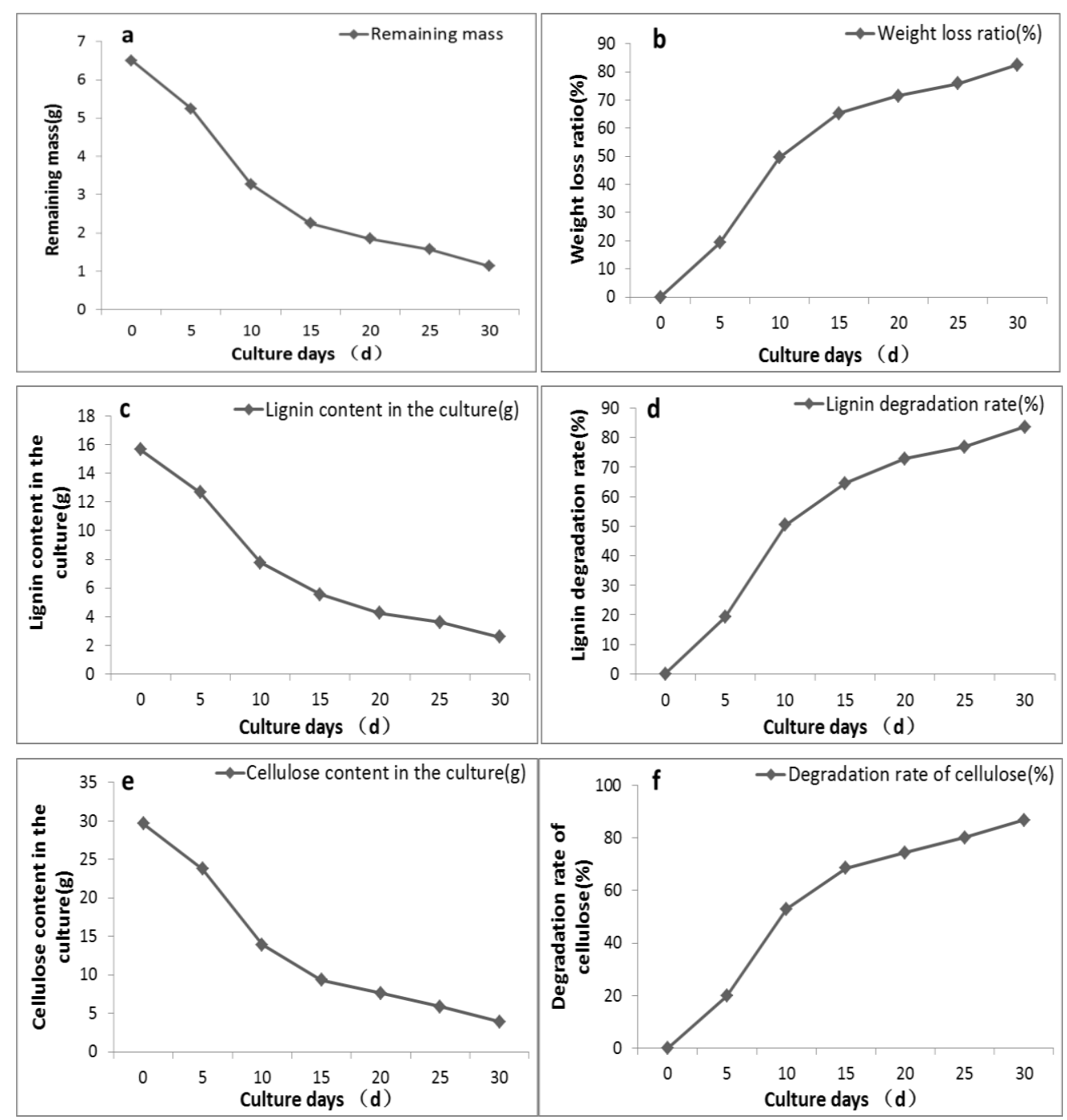

Figure 2 Mass loss and degrading rate of lignin cellulose

\section{Conclusions}

Research results showed that the natural dry material and the ratio of liquid medium has a larger effect on fungi degradation of lignin, humidity is too high and too low, when the material liquid ratio of 1:4 (w/v) as the highest absolute biological efficiency, reduction of lignin, cellulose and hemicellulose relative to the oxygen content at the same time, additional nutritional powerhouses such as nitrogen source, the variety and dosage of carbon sources on biological delignification also have great influence on biological lignin.

From the experiment result showed liquid culture delay the laccase production peak, laccase production peak during $15 \mathrm{~d}(1842.9 \mathrm{U} / \mathrm{L})$. When the training period of $30 \mathrm{~d}$, straw powder dry matter weight loss rate of $82.48 \%$, the cellulose degradation of lignin were $83.57 \%, 86.85 \%$, showed the 4222 to the degradation of corn straw has a good ability, can be used as the good candidate for the straw lignin degradation bacteria. Straw in the solid medium culture 4222 bacteria produce laccase activity and laccase production peak time and there are differences in liquid fermentation, shows two kinds of cultivation mode could different enzyme production mechanism, the existence of natural wheat grass meal has a certain influence on the secretion of laccase. In the process of lignocellulose degradation, laccase production has played a key role, but it is not the result of a single action. Laccase production level and the degradation of lignocellulose ability 
strong and the weak, there is no necessary correlation, such as research of lignin degradation model bacteria spore hairs ping huang leather bacteria (Phanerochaete chrysosporium) is a typical example, it is usually very few secrete laccase, but to the lignocellulose has strong degradation ability.

\section{Acknowledgements}

This work was financially supported by the Jilin National Natural Science Foundation (31471926).

\section{References}

[1] Zhu jian-chun, Li rong-hua, Yang xiang-yun, Zhang zeng-qiang, Fan zhi-min. Spatial and temporal distribution of crop straw resources in 30 years in china. Journal of Northwest A \&F University (Nat. Sci. Ed), 40:139-145, (2012).

[2] LIU Li- xiang, WU Cheng-zhen, HONG Wei, LI Jian, CAI Bing-ling, LIN Shu-wei. Advances in comprehensive utilization of crop straw, subtropical Agriculture Research, (2), p. 75-80, (2006).

[3] KAZUYUKI SAITO, TETSUZO YASUNARI and JUDAH COHEN. International Journal of Climatology, (24): p. 33-44, (2004).

[4] Fabio Vianello, Antonio Cambria, Santa Ragusa, Maria Teresa Cambria, Lucio Zennaro, Adelio Rigo. A high sensitivity amperometric biosensor using a monomolecular layer of laccase as biorecognition element, Biosensors and Bioelectronics, (20) :315-321, (2004).

[5] Corinne Jolivalt, B Leiningermuller, Philippe Bertrand, Regine Herber, Yves Christen, Gerard Siest. Differential oxidation of apolipoprotein E isoforms and interaction with phospholipids, Free Radical Biology and Medicine, (28): p. 129-140, (2000).

[6] Eggert C, Temp U, Eriksson K E. The ligninolytic system of the white rot fungus Pycnoporus cinnab arinus: Purification and characterization of the laccase. Appl Environ Microbiol, 62(4):1151-1158,(1996)

[7] Alcalde, M. . Laccases: biological functions, molecular structure and ind ustrial applications. In: Polaina, J., MacCabe, A.P. (Eds), Ind ustrial Enzymes, VII ed. Springer, (2007) p. 461-476.

[8] Baldrian, P., 2006. Fungal laccases e occurrence and properties. FEMS Microbiol. Rev. 30, 215-242.

[9] Strong, P.J., Claus, H.. Laccase: a review of its past and its future in bioremediation. Crit. Rev. Environ. Sci. Technol. 41, p. 373-434. (2011)

[10] Desai, S., Nityanand, C.. Microbial laccases and their applications: a review. Asian J. Biotechnol, 3, p. 98-124. (2011)

[11] Rodriguez Couto, S., Toca Herrera, J.L., 2006. Industrial and biotechnological applications of laccases: a review. Biotechnol. Adv. 24, 500-513.

[12]Claudia M. RIVERA-HOYOS, Edwin David MORALES- ALVAREZ, Raul A. POUTOU-PINALES, Aura Marina PEDROZA- RODRIGUEZ, Refugio RODRIGUEZVAZQUEZ, Julio M. DELGADO-BOADA. Fungal laccases, (2013) 27, p. 67 -82

[13] R. C. Minussi, M. A. Miranda, J. A. Silva et al., Purification, characterization and application of laccase from Trametes versicolorfor colour and phenolic removal of olive mill wastewater in the presence of 1-hydroxybenzotriazole, African Journal of Biotechnology, 6, p. 1248-1254. (2007)

[14] Buddolla Viswanath, Bandi Rajesh, Avilala Janardhan, Arthala Praveen Kumar, and Golla Narasimha. Fungal Laccases and Their Applications in Bioremediation, Enzyme Research, 21 
(2014).

[15] Shraddha, R. Shekher, S. Sehgal, M. Kamthania, and A. Kumar, "Laccase: microbial sources, production, purification, and potential biotechnological applications", Enzyme Research, (2011).

[16] J. C. Gonzalez, S. C. Medina, A. Rodriguez, J. F. Osma, and C. J. Almeciga-Diaz, "Production of Trametes pubescens laccase under submerged and semi-Solid culture conditions on agro-Ind ustrial wastes," PLoS ONE, vol. 8, (2013).

[17] P JVan Soest, J BRobertson, Betty ALewis. Methods for Dietary Fiber, Neutral Detergent Fiber, and Nonstarch Polysaccharides in Relation to Animal Nutrition Journal of Dairy Science, (1991). 